Гусарова Марина Александровна

доктор философских наук, кандидат

социологических наук, доцент, доцент кафедры

общетеоретических правовых дисциплин

Северо-Кавказского филиала Российского

государственного университета правосудия

\section{ПРОБЛЕМА ИНТЕГРАТИВНОГО ПОДХОДА К ПОНИМАНИЮ ПРАВА И ГОСУДАРСТВА В ФИЛОСОФСКО-ПРАВОВОМ ТВОРЧЕСТВЕ Н.Н. АЛЕКСЕЕВА}

\section{Аннотация}

Статья посвящена исследованию идей о праве и государстве известного российского правоведа Н.Н. Алексеева. Автор акцентирует внимание на роли евразийства как идейно-мировоззренческого и общественно-политического течения в становлении оригинальной методологии Н.Н. Алексеева по вопросам, касающимся права и правовых явлений. Рассмотрены философско-правовые взгляды ученого на право как феномен, обусловленный особенностями исторического и социокультурного развития того или иного общества и государства. Показано соотношение внутренних основа ний права и внешних, институциональных фоорм его реализации с точки зрения интегративного подхода, позволяющего преодолеть односторон ность и недостатки позитивистского и естественно-правового подходов. Делается вывод об актуальности идей Н.Н. Алексеева в современных условиях многонациональности и многоконфессиональности, а также активного реформирования российского общества в процессе построения правового государства.

Ключевые слова:

право, государство, западничество, славянофильство, евразийство, правопонимание, субъект права, правосознание, интегративный подход, Н.Н. Алексеев.
Gusarova Marina Aleksandrovna

D.Phil., PhD in Social Science,

Associate Professor, General

Theoretical and Legal Department

North Caucasus Branch

of Russian State University of Justice

\section{THE PROBLEM OF INTEGRATIVE APPROACH TO UNDERSTANDING LAW AND STATE IN PHILOSOPHICAL AND LEGAL WORKS BY NIKOLAY ALEKSEEV}

The present research deals with the study of ideas about law and state of a famous Russian jurist Nikolay Nikolaevich Alekseev. The author focuses on the role of Eurasianism as an ideological, worldview as well as social and political trend in development of the original methodology of Nikolay Alekseev regarding the issues related to law and legal phenomena. There are considered philosophical and legal views of the scientist on law as a phenomenon determined by the features of historical and socio-cultural development of a particular society and state. The research provides the ratio of internal and external foundations of law, institutional forms of its implementation in the context of an integrative approach which allows to overcome the one-sidedness and shortcomings of positivistic and natural law approaches. It is concluded that the ideas of Nikolay Alekseev are relevant in modern conditions of a multiethnic and multi-confessional Russian society, as well as its active reforming in the process of building a legal state in Russia.

Keywords: law, state, Westernism, Slavophilism, Eurasianism legal thinking, legal subject, legal consciousness, integrative approach, N.N. Alekseev.

В условиях построения правового государства и гражданского общества в современной России изучение сущности правовых и государственных феноменов приобретает особую актуальность. Усиление влияния глобализационных процессов, стимулировавших участие государства в международных правовых отношениях, неизбежно приводит к необходимости осмысления не только современных фракторов, обусловливающих правовую жизнь, но и объективно-исторических оснований, благодаря которым формировалась отечественная теория права.

Одной из фигур, оказавших серьезное влияние на формирование учения о праве и государстве в дореволюционной России, а затем - на виднейшие умы российской научной эмиграции, является Николай Николаевич Алексеев. Он не только затрагивал узкие государственноправовые проблемы российского и советского общества в своих трудах, но и обращался к осмыслению русской национальной идеи и российского правового сознания как основополагающих, центростремительных феноменов в процессе построения правового учения.

Несмотря на повышенный научный интерес к теории Н.Н. Алексеева со стороны современных авторов, некоторые аспекты его учения о праве и государстве заслуживают детального исследования. Речь идет прежде всего об оригинальной интегративной методологии, позволившей в рамках фрилософско-правовых размышлений ученого «примирить» противоборствующие западническую и славянофильскую позиции в вопросах о сущности права и государства, а также о соотношении внутренних социокультурных оснований права и внешних, институциональных форм его реализации. 
Итак, на методологию, использованную Н.Н. Алексеевым в описании правовых феноменов, оказала влияние приверженность ученого к евразийскому течению философии, основы которого были изложены в ряде работ разных лет [1]. Следует отметить, что к евразийским идеям Н.Н. Алексеев пришел в результате внутренних духовных борений, продолжавшихся многие годы в его творчестве. Как отмечает в предисловии к одному из трудов Н.Н. Алексеева професcop B.A. Томсинов, в начале своей научной карьеры, подобно многим интеллектуалам начала XX в., ученый разделял взгляды западников, чему способствовали непродолжительные научные командировки за границу, знакомство с первоисточниками по общественно-правовой проблематике, а также личное общение с ведущими философрами и правоведами университетов Берлина, Гейдельберга и Парижа. Однако более длительное проживание среди местного населения Европы, в частности среди немцев, осмысление исторического пути России, а также социальных причин кризисных явлений в российской социальной реальности, по словам В.А. Томсинова, убедили Н.Н. Алексеева в уникальности российской культуры, путь формирования которой обусловлен особыми геополитическими и историческими факторами [2]. А.С. Амбарцумян [3, с. 84] и И.В. Новоженина [4, с. 9] также подчеркивают влияние на фоормирование правовых идей Н.Н. Алексеева в ранний период его творчества кантианских идей.

Важно отметить, что в научном творчестве Н.Н. Алексеева от неокантианства к евразийству его незримо сопровождал опыт противоборствовавших на протяжение всего XIX в. философских течений западников и славянофилов, что не могло не отразиться на его правовой концепции. Однако, в отличие от его великих предшественников, Н.Н. Алексеев отказался от противоположных друг другу стратегий в выборе направления общественного развития России и предпринял попытку поиска «золотой середины» между западнической и славянофильской позициями. Так, с точки зрения евразийского подхода, утверждается принцип культурного дуализма российской цивилизации, обусловливающий органичный симбиоз западно-европейских и азиатских ценностно-нормативных систем, исключающий всякую попытку сближения либо с Востоком, либо с Западом как дегенеративного для России процесса. При этом соединение в российском сознании таких черт, как стремление к традиционализму, консерватизму и вместе с тем - к технологическому прорыву, что выражается в смелости научной мысли, является, по мнению евразийцев П.Н. Савицкого, Н.С. Трубецкого, Г.В. Флоровского и др., залогом внутреннего потенциала для успешного развития российского общества. Как справедливо указывают современные исследователи В.В. Ячевский и Т.В. Колесникова, заслугой Н.Н. Алексеева является разработка трактовки права как феномена без участия западного правосознания, что отвечает уникальному «месторазвитию» России в его евразийском контексте [5, с. 50].

Н.Н. Алексеев утверждал, что российское правопонимание основывается на таких духовных ценностях, коренящихся в глубинах российской культуры, как стремление к «внутренней правде» и справедливости. Начала российской государственности Н.Н. Алексеев также ищет во «внутренней» свободе и правде. В одном из его трудов отмечается следующее: «Свободное согласие пронизало отношения между властвующими и подвластными, которые соединялись единым нравственным убеждением, а не формальной юридической нормой, не правовыми гарантиями. <...> Вся сила в идеале. Да и что значат условия и договоры, как скоро нет силы внутренней! Основой государства была не “внешняя правда", а “правда внутренняя", т. е. внутреннее убеждение и связанное с ним “бытовое предание”. На твердости быта, проникнутого началами православной религии, а не на нормах римского права, как это было на Западе, покоилось все русское государство. Цельность бытового бытия - вот что составляло фундамент России, и она представляла собою истинно нравственное целое, приближающееся к идеалу» [6, с. 271]. В данном утверждении нельзя не заметить апеллирование к идеям славянофилов А.С. Хомякова, И.В. Киреевского, бр. Аксаковых, разделявших в основном естественно-правовые взгляды и обосновавших русский социальный идеал соборности и единства, основанный на христианском принципе братской любви, взаимной ответственности, «внутренней правды» и справедливости как основы российского понимания права [7].

Солидаризируясь с социально-философскими идеями славянофилов, Н.Н. Алексеев констатировал наличие социокультурного разрыва между жизнью высших классов и широких народных масс, породившего принципиальные противоречия в понимании правовых и государственно-политических явлений. По мнению ученого, построенная высшими классами общая теория права оказалась малопонятной и чуждой народу, поскольку базировалась на индивидуалистических началах западноевропейской науки. Для народного же понимания сущности и назначения права, по словам Н.Н. Алексеева, традиционно было свойственно интуитивное понимание, отличающееся от западного правопонимания, но вместе с тем и не совпадающее с воззрениями народов чисто восточных [8, с. 270]. В другом произведении Н.Н. Алексеева подтверждается идея о необходимости отказа от принципа европоцентризма и принятии во внимание синтетического опыта истории цивилизации 
в процессе построения правовой науки. Ученый отмечает: «Курьезно "общую теорию государства" строить на опыте последних ста лет европейской истории и отбрасывать тысячелетний опыт истории древних культур. Такая история будет всем, чем угодно, но не наукой» [9, с. 17]. Иными словами, самобытностью и неповторимостью российская правовая жизнь обязана особенным чертам правовой культуры, сформировавшимся одновременно под влиянием западной и восточной цивилизаций, ценности которых были успешно интегрированы российским обществом.

Среди объективных факторов, обусловивших становление российской государственности, Н.Н. Алексеев особенно выделял процесс колонизации, в ходе которого проявились стремление российского народа к достижению свободы и склонность к экстенсивному способу организации жизни. В одной из работ он отмечал следующее: «На Западе, если государство давило, можно было придумать только один исход: усовершенствовать государство и ослабить давление. У нас государство давило по необходимости, но мы не стремились усовершенствовать государство, а уходили от него в степь и леса. Государство настигло ушедших - они опять уходили дальше. Так и протекал процесс колонизации» [10, с. 273-274]. Далее он пишет, что «уход от государства есть первостепенный фракт русской истории, который физическое свое воплощение нашел в казачестве и свое нравственное оправдание - в различных политических воззрениях, оправдывающих бегство от организованных политических фрорм общественной жизни» [11, с. 274]. Таким образом, по мнению Н.Н. Алексеева, нравственно ориентированный характер российского общественного правосознания, боязнь и недоверие государственно-политическим формам организации общественной жизни вытекали из исторических условий формирования российского государства.

Описывая евразийское государство как государство правовое, Н.Н. Алексеев подчеркивал, что в нем преодолевается односторонность европейских и азиатских государств. Ученый пишет об этом следующее: «...в истинно совершенном государстве, кроме права, должны господствовать также и моральные силы - силы любви, дружбы, солидарности, жертвенности, служения и подвига. Если бы возможно было полное, доходящее до отождествления, проникновение государства правом, то все эти нравственные силы поистине были бы обречены на полное угасание. И это было бы в то же время угасанием государства, превращением его в состояние принудительной тюрьмы или в состояние неорганизованной анархии» [12, с. 201-202].

Парируя нормативистской позиции как односторонней и не лишенной недостатков с точки зрения возможности охвата всех аспектов правовой жизни, Н.Н. Алексеев замечал, что «нормальная правовая система должна предполагать, что установленный ею объективный порядок справедливости находит какое-то отражение во внутренней духовной жизни членов правового общения, что этот порядок согласуется как-то с справедливостью как внутренней добродетелью» [13, с. 121]. В фокус критического анализа ученого попадают идеи ведущего представителя юридического позитивизма Г. Кельзена, развитые в труде «Основные проблемы учения о государственном праве...» [14], о том, что феномен нормативности лежит исключительно в сфере должного, поэтому трактовка права должна осуществляться не исходя из его идеальных состояний, но основываясь на сфере социальных фрактов. Параллельно с Кельзеном ученый анализирует суждения представителя социологического позитивизма - Л. Дюги о приоритете социальных норм в качестве общественных регуляторов поведения и порядка [15]. В данной точке зрения Н.Н. Алексеев признает наличие обоснованных моментов, но сам фракт возможности признания социальных норм и возведения их в статус государственно охраняемых заставляет ученого отнести концепцию Дюги к еще одному варианту «отождествления государственного регулирования с регулированием правовым» [16, с. 497]. Критике в трудах Н.Н. Алексеева подвергается также достаточно популярная в европейском научном сообществе того времени теория насилия Л. Гумпловича, согласно которой государства как институты и союзы есть результат насилия одного племени над другим, результат насильственного покорения [17].

В противовес указанным авторам Н.Н. Алексеев определяет государство не как механический союз бездуховных и безвольных субъектов, возникший в результате насилия, но как союз разумных субъектов, способных коммуницировать друг другом и упорядочивающих данный процесс с помощью права. Он пишет, в государстве осуществляется «властвование над людьми и в средь людей... властвование над разумными и духовными существами, способными входить друг с другом в общение» [18, с. 38]. В правовой структуре одним из важнейших элементов является субъект права как сознательная, волевая единица социальных взаимодействий, обнаруживающая ценности во внешнем мире. Н.Н. Алексеев пишет об этом следующее: «До тех пор, пока носитель правового смысла и излучающееся из него правосознание не достигнут нормальной истинно-духовной жизни, порождающей нормальную и здоровую жизнедеятельность, - до тех пор и право не сможет быть совершенным» [19, с. 223-224]. Отсюда следует, что любые изменения в правовой системе и государстве должны производиться с согласия субъектов права и быть соизмеряемы с их ценностями. 
Нельзя не отметить, что в системе взаимодействия «государство - право - индивид» Н.Н. Алексеев выделяет френомен внутренних оснований, приводящих правосознание в движение. Речь идет о силе влияния различных социальных нормативных систем на формирование правовых мотиваций и ценностей. «До тех пор, пока мы философским, духовным, нравственным и религиозным опытом не познали, что такое истинно святое и ценное и что в порядке ценного является высшим и низшим, - до тех пор мы не сможем решить вопрос о правильном и справедливом праве» [20, с. 224]. Далее он отмечает: «Нужно духовный опыт познания сделать соборным опытом, считаясь с историческими условиями, построить на нем систему учреждений, которые отражали бы в себе истинно святое и ценное. Познание путей подобного воплощения ценностей или одухотворения правовой жизни и есть задача правовой тактики или правовой политики, т. е. искусство реализации ценностей» [21, с. 205]. Иными словами, в концепции Н.Н. Алексеева, во-первых, описывается процесс формирования здорового правосознания личности, исходящий в начале своего пути из высших нравственных, религиозных, философских ценностей с последующей их эстериоризацией в правовом поведении. Во-вторых, обосновывается весьма важная для современного российского общества идея о необходимости апеллирования правовых ценностей к нравственным идеалам должного, которые, в свою очередь, складываются в коллективном общественном сознании под влиянием исторических фракторов. Следовательно, нарушение данной логики, согласно Н.Н. Алексееву, чревато неэффективностью и тщетностью любых преобразований извне.

Отрицая идею славянофилов о ничтожности правовых преобразований в деле переустройства общества и вместе с тем не соглашаясь с позицией западников о необходимости коренной ломки общественных устоев, Н.Н. Алексеев настаивал на целесообразности внедрения идеальных начал в структуру правовых институтов, демонстрируя таким образом важность синтеза предложений о реформировании общества, выдвинутых представителями обоих философских направлений. Он призывал современников заниматься не «отысканием конечной формулы общественного совершенства (хотя и она необходима в определенной степени, ибо без нее вообще не обойтись), но указанием тех действительных путей и средств, при помощи которых может быть улучшен всякий возможный правопорядок, - в полном сознании, что подобное улучшение может излечить многие болезни общества, но не в состоянии преобразовать общество в целом и довести его до состояния земного рая» [22, с. 48]. Иными словами, идеализация влияния духовных оснований без соответствующего им институционального воплощения в жизни, по мнению ученого, обречена на провал.

Как представляется, в приведенных выше суждениях Н.Н. Алексеевым достаточно успешно предпринята попытка синтетического подхода к определению государственных и правовых явлений, что позволяет отнести ученого, помимо П.А. Сорокина, А.С. Ященко, П.Г. Виноградова [23] и др., к первопроходцам синтетического правопонимания.

В отличие от остальных евразийцев-современников, например П.Н. Савицкого, Н.С. Трубецкого и Г.В. Флоровского, Н.Н. Алексеев не анализировал глубоко архетипические черты российского сознания, не акцентировал внимание на национально-культурном наследии российского народа в духе евразийского философского направления. Однако принадлежность к данному течению, на наш взгляд, позволила Н.Н. Алексееву применить по сути синтетический, интегративный подход, благодаря которому ученый сделал ряд следующих выводов: обосновал идею о необходимости аксиологического компромисса между западными и восточными идеалами в основе российского общественного сознания; описал социально-психологический механизм взаимосвязи правовой и государственной жизни; доказал актуальность идеи о важности согласия внешних, исходящих от государства, изменений с исторически обусловленными основаниями общественного правосознания.

Нельзя не подчеркнуть, что, несмотря на принадлежность взглядов Н.Н. Алексеева к «высокой» правовой теории и незавершенность в качестве единой системы, идеи ученого приобретают особую актуальность в современной России, в частности в условиях многонациональности и многоконфессиональности общества и направленной на построение правового государства правовой политики.

\section{Ссылки:}

1. См.: Евразийство. Декларация, формулировка, тезисы. Прага, 1932. 28 с. ; Утверждение евразийцев. Кн. 1. Исход к Востоку. Предчувствия и свершения. Статьи П.Н. Савицкого, П.П. Сувчинского, кн. Н.С. Трубецкого и Г.В. Флоровского. София, 1921. 125 с. ; Утверждение евразийцев. Кн. 2. На путях. Статьи П.Н. Савицкого, А.В. Карташёва, П.П. Сувчинского, кн. Н.С. Трубецкого, Г.В. Флоровского, П.М. Бицилли. М. ; Берлин, 1922.358 с.

2. Томсинов В.А. Николай Николаевич Алексеев (1879-1964). Биографический очерк // Алексеев Н.Н. Очерки по общей теории государства. Основные предпосылки и гипотезы государственной науки / под ред. и с предисл. В.А. Томсинова. М., 2008. 216 с. 
3. Амбарцумян А.С. Становление и развитие политико-правовой концепции Н.Н. Алексеева // Гуманитарные и социально-экономические науки. 2013. № 5 (72). С. 83-88.

4. Новоженина И.В. Государственно-правовое учение Н.Н. Алексеева : автореф. дис. ... канд. юрид. наук. Уфа, 2002. 22 с.

5. Ячевский В.В., Колесникова Т.В. Евразийцы и право // Вестник Воронежского государственного университета. Серия: Право. 2010. № 2 (9). С. 49-56.

6. Алексеев Н.Н. Русский народ и государство. М., 1998. 640 с.

7. Подробнее см.: Гусарова М.А. Проблема духовных оснований русского правосознания в социально-фрилософрских учениях славянофилов // Исторические, философские, политические и юридические науки, культурология и искусствоведение. Вопросы теории и практики. 2016. № 11-2 (73). С. 88-90.

8. Алексеев Н.Н. Русский народ и государство. С. 270.

9. Алексеев Н.Н. Теория государства. Теоретическое государствоведение. Государственное устройство. Государственный идеал. Париж, 1931. 137 с.

10. Алексеев Н.Н. Русский народ и государство. С. 273-274.

11. Там же. С. 274.

12. Алексеев Н.Н. Основы фрилософии права / вступ. ст. А.П. Альбова [и др.]. СПб., 1998. 215 с.

13. Там же. С. 121.

14. Kelsen H. Hauptprobleme der Staatsrechtslehre, entwickelt aus der Lehre vom Rechtssatz. Tübingen, 1911. XXVII, 709 S.

15. Duguit L. L'Etat: les gouvernants et les agents. Vol. 2. Paris, 1903. 774 p.

16. Алексеев Н.Н. Русский народ и государство. С. 497.

17. Gumplowicz L. Allgemeines Staatsrecht. 3. verm. und verb. Aufl. Innsbruck, 1907. XV, 540 S.

18. Алексеев Н.Н. Очерки по общей теории государства. Основные предпосылки и гипотезы государственной науки. M., 2008. $216 \mathrm{c}$.

19. Алексеев Н.Н. Основы фрилософии права. СПб., 1999. 251 с.

20. Там же. С. 224.

21. Там же. С. 205

22. Там же. С. 48.

23. Подробнее см.: Гусарова М.А. К вопросу об истоках интегративного правопонимания в трудах П.А. Сорокина, А.С. Ященко, П.Г. Виноградова // Теория и практика общественного развития. 2019. № 8 (138). С. 29-33. https://doi.org/10.24158/tipor.2019.8.4.

\section{References:}

Alekseev, NN 1931, Theory of the State. Theoretical Constitutional Law. State Structure. Ideal State, Paris, 137 p., (in Russian). Alekseev, NN 1998, Fundamentals of Philosophy of Law, in AP Albova (comps), St. Peterburg, 215 p., (in Russian).

Alekseev, NN 1998, Russian People and State, Moscow, 640 p., (in Russian).

Alekseev, NN 1999, Fundamentals of Philosophy of Law, St. Peterburg, 251 p., (in Russian).

Ambartsumyan, AS 2013, 'Creation and Development of a Political and Legal Conception by N.N. Alekseev', Gumanitarnye i Sotsialno-Ekonomicheskiye Nauki, no. 5 (72), pp. 83-88, (in Russian).

Duguit, L 1903, L'Etat: les Gouvernants et les Agents, vol. 2, Paris, 774 p.

Eurasianism. Declaration, Definition, Bullet Points, Prague, 1932, 28 p., (in Russian).

Gumplowicz, L 1907, Allgemeines Staatsrecht, Innsbruck, XV, 540 S.

Gusarova, MA 2016, 'Issue of Spiritual Background of Russian Legal Awareness in Social and Philosophical Theories of Slavophils', Istoricheskiye, filosofskie, politicheskiye i yuridicheskiye nauki, kulturologiya i iskusstvovedeniye. Voprosy teorii i praktiki, no. 11-2 (73), pp. 88-90, (in Russian).

Gusarova, MA 2019, 'On the Origins of Integrative Legal Thinking in the Works of P.A. Sorokin, A.S. Yashchenko and P.G. Vinogra-

dov', Teoria i praktika obshchestvennogo razvitia, no. 8 (138), pp. 29-33, https://doi.org/10.24158/tipor.2019.8.4, (in Russian).

Kelsen, H 1911, Hauptprobleme der Staatsrechtslehre, Entwickelt aus der Lehre vom Rechtssatz, Tübingen, XXVII, 709 S. Novozhenina, IV 2002, State Legal Theory of N.N. Alekseev, PhD thesis, Ufa, 22 p., (in Russian).

Strengthening of Eurasians. Book 1. Exodus to the East. Anticipations and Achievements. Articles by P.N. Savitsky, P.P. Suvchinsky, books by N.S. Trubetskoy and G.V. Florovsky 1921, Sofia, 125 p., (in Russian).

Strengthening of Eurasians. Book 2. On the Way. Articles by P.N. Savitsky, A.V. Kartashyov, P.P. Suvchinsky, books by

N.S. Trubetskoy, G.V. Florovsky, P.M. Bicilli 1922, Moscow, Berlin, 358 p., (in Russian).

Tomsinov, VA 2008, 'Nikolay Nikolaevich Alekseev (1879-1964). A Biographical Sketch', Alekseev N.N. Outline of General

Theory of State. Basic Preconditions and Assumptions of the Science about State, Moscow, 216 p., (in Russian).

Yachevsky, VV \& Kolesnikova, TV 2010, 'Eurasians and Law', Vestnik Voronezhskogo gosudarstvennogo universiteta, Ser.:

Pravo, no. 2 (9), pp. 49-56, (in Russian). 